Kayode Omowumi Titilola, Rotimi Damilare Emmanuel, Afolayan Olubisola Arike, Kayode Azeez Abideen Abolanle. Ketogenic diet: A nutritional remedy for some metabolic disorders. Journal of Education, Health and Sport. 2020;10(8):180-188. eISSN 2391-8306. DOI http://dx.doi.org/10.12775/JEHS.2020.10.08.021

https://apcz.umk.pl/czasopisma/index.php/JEHS/article/view/JEHS.2020.10.08.021

https://zenodo.org/record/3977888

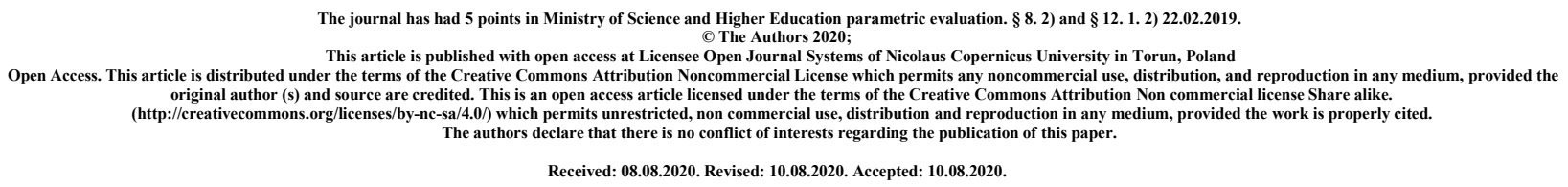

\title{
Ketogenic diet: A nutritional remedy for some metabolic disorders
}

Kayode Omowumi Titilola ${ }^{1}$, Rotimi Damilare Emmanuel ${ }^{1}$, Afolayan Olubisola Arike ${ }^{2}$, Kayode Azeez Abideen Abolanle ${ }^{3}$

${ }^{1}$ Department of Biochemistry, Landmark University, P.M.B 1001, Omu Aran, Kwara State, Nigeria

${ }^{2}$ Department of Science Laboratory Technology, Federal Polytechnic Ilaro, P.M.B 50, Ilaro, Ogun State, Nigeria

${ }^{3}$ Department of Biochemistry, Babcock University, Ilishan-Remo, Ogun State, Nigeria

Corresponding author: Kayode A. A. Abolanle, E-Mail: kayodeab@babcock.edu.ng

\begin{abstract}
Background: Ketogenic diets (KD) consist of high fat, moderate protein and low carbohydrates. Aim: This review explores the effect of ketogenic diet and its mechanism of actions in disease management.

Methods: Recent information on ketogenic diets and disease management were retrieved from academic journals using scientific search engines and popular library databases such as PubMed, Scopus, Web of Science, JSTOR amongst others.

Commentary: Ketogenic diet means a high fat, low-carbohydrate diet, with enough protein content, which makes the body utilize fat, rather than carbohydrate, as a preferred energy source. There are four different types of ketogenic diet, the traditional classic ketogenic diet, medium chain triglyceride (MCT) ketogenic diet, the modified Atkins diet (MAD), and the low glycemic index treatment (LGIT). The classic ketogenic diet, also known as long-chain fats consist of 1620 carbon atoms. Its peculiarity is the low carbohydrate content, which could be difficult to maintain. The MCT was developed as an alternative to classic ketogenic diet. It has a fat composition of $60 \%$ octanoic acid (eight-carbon fatty acid) and $40 \%$ decanoic acid (10-carbon fatty acid). The MCT provides about $45 \%$ of energy when compared with the classic ketogenic diet. The MAD though strongly encourages the intake of high fat, it allows for $10-20 \mathrm{~g}$ of carbohydrate per day. The LGIT permits only low glycemic index foods. Ketogenic diets have been a therapeutic strategy for several diseases such as obesity, dyslipidemia, cancer and a broad
\end{abstract}


range of neurological disorders.

Conclusion: The ketogenic diet, an effective and age-long treatment for epilepsy in children, is gradually gaining acceptance as a therapeutic modality for many other diseases.

Key words: Ketogenic diet, nutritional remedy, diseases, metabolic disorders

\section{INTRODUCTION}

Ketogenic diet comprises of high fat contents such as butter, eggs, cheese, fish, mayonnaise and cream; moderate protein and low carbohydrate component. It eliminates high carbohydrate foods such as bread, starchy food including vegetables, sugar and grains. ${ }^{1}$ This results in reduced carbohydrate and protein metabolism but increased high fat metabolism. Consequently, there is high ketone bodies derived from fat and reduced blood glucose level, which alters energy metabolism. ${ }^{2}$ Weight ratio of ketogenic diet to carbohydrate diet (combined with protein), is 4:1. The primary aim of the treatment with ketogenic diet is to metabolize fats rather than carbohydrates as the energy source for the body, thereby shifting production of energy to ketosis and increasing ketone bodies levels in the body. Subsequently, substrates required in the brain like ATP, phosphocreatine and creatine are increased as ketone bodies increases. Medium chain triglycerides, coconut oils supplements diets and modified Atkins diet have been reported to have same effect as the ketogenic. This induces a physiologic starvation. Ketogenesis has also been observed to result in reduction in glucose breakdown due to low amount ingested. The reduction causes decreased synaptic excitability of the neuron, which caused increased seizure threshold. ${ }^{2}$

Ketosis is a metabolic condition where the main energy source is ketone bodies metabolism as opposed to glucose. The body metabolizes ketone during fasting or during low carbohydrate intake into the body. ${ }^{3}$ In the year 1921, four different types of ketogenic diets were established. They were long chain triglycerides (LCT) diet, medium chain triglyceride (MCT) diet, modified Atkins diet and low glycaemic index treatment (LGIT). The long chain triglycerides (LCT) diet is the most popular of the ketogenic diets. It is also referred to as classic ketogenic diets and its ratio is $4: 1$ or could be $3: 1,2: 1$ or 1:1. The MCT diet was established to counter the high fat diet obtained in the LCT diet. ${ }^{4}$ The basic fat components in MCTs are lauric acids, capric acid, caprylic acids, and caproic acid. ${ }^{5}$ Its ketone composition is based not on diet ratios but calories percentage from MCTs oils. MCTs is preferred to LCTs because MCTs are absorbed efficiently and transported faster to the liver by albumin. After liver uptake, they undergoes $\beta$-oxidation of the fatty acids, which produces acetyl CoA, the precursors for ketone bodies synthesis. LCTs are therefore integrated with chylomicrons and transported through thoracic duct in the blood. Metabolism of LCTs requires more energy and occurs at a slower rate than that of MCTs because LCT diets requires a carnitine carrier to be transported into the mitochondria before $\beta$ oxidation of the fatty acids can occur. Therefore, to attain the desired ketosis, MCTs should contain less total fat. ${ }^{6}$

The modified Atkins diet, established and examined at Johns Hopkins Hospital was aimed at recommending a highly delicious and less controlled dietary treatment. It does not restrict protein 
intake while LGIT allows moderate carbohydrate intake with glycemic index less than 50 without increased ketone level. LGIT encourages lower rise in blood glucose. ${ }^{7,8}$

All the different ketogenic diets composition must be prepared or monitored by a dietician/nutritionist to establish the right ketone level and this could be based on criteria such as age, weight, gender, activity level and clinical diagnosis. Monitoring of ketogenic diets patients require great commitment and motivation to sustain and undertake ketogenic diets successfully. ${ }^{3}$

Insulin is responsible for metabolism during well-fed state. It ensures the cell is supplied with the required fuel derived from carbohydrate (glucose) or fat, this could then be stored in form of glycogen or triacylglycerol. Reduced blood glucose concentration decreases insulin level that results into depleted storage and energy expenditure. Therefore, the body sought for alternative fuels. The metabolism of ketogenesis begins in the liver by the oxidation of fatty acids in the mitochondria matrix that produces acetyl CoA. The product (acetyl CoA) either proceeds into tricarboxylic acid cycle or reacts to produce ketone bodies due to excess production of acetyl $\mathrm{CoA}$ in the cell. The ketone bodies, which are acetone, acetoacetate and 3-hydroxybutyrate, are transported from the liver to the blood and thereafter to different tissues such as the brain. Acetone has been observed to be poorly metabolized and acetoacetate is chemically unstable whereas 3-hydroxybutyrate is well circulated in the blood. ${ }^{7}$

Under physiological condition, ketone concentration is low in the plasma (less than $0.2 \mathrm{mM}$ ) but could rise as high as $7-8 \mathrm{mM}$. The brain and the muscle degrades ketone bodies to acetyl CoA as a source of energy that is catalyzed mainly by hydroxybutyrate dehydrogenase and succinyl-CoA: 3-ketoacid CoA transferase. High hydrogen to carbon ratio observed in ketone bodies makes it more energetically efficient than fatty acids or pyruvate and this means they do not uncouple mitochondria unlike fatty acids. Acetoacetate overproduction could lead to ketonuria and ketonemia (elevated ketone level in urine and blood). Acetone, a volatile substance, causes the 'sweet' breath odour of ketosis. ${ }^{3}$

Table 1: Composition and pros/cons of the different ketogenic diets

\begin{tabular}{|c|c|c|c|}
\hline Diet & $\begin{array}{l}\text { Compositio } \\
\text { n }\end{array}$ & Pros & Cons \\
\hline $\begin{array}{l}\text { Classical } \\
\text { KD }\end{array}$ & $\begin{array}{l}\text { Can be } \text { any } \\
\text { ratio but } \\
\text { typically } 3- \\
4: 1 \quad \text { Based } \\
\text { on } 4: 1 \text { ratio: } \\
90 \% \text { fat, } \\
4 \% \\
\text { carbohydrat } \\
\text { e, } 6 \% \\
\text { protein }\end{array}$ & $\begin{array}{l}\text { Parents know exactly how } \\
\text { much of each food to give; } \\
\text { Very consistent, therefore } \\
\text { little variation in ketones; } \\
\text { Easy to adjust as dietician } \\
\text { knows exactly what child is } \\
\text { getting; Requires less record } \\
\text { keeping by parents }\end{array}$ & $\begin{array}{l}\text { Difficult to adjust amount consumed } \\
\text { based on child's appetite; } \\
\text { Child must eat everything on their } \\
\text { plate; } \\
\text { Protein limited to recommended } \\
\text { dietary allowance, } \\
\text { which is often less than child is used } \\
\text { to; Involves weighing and measuring; } \\
\text { more time-consuming to prepare the } \\
\text { meals }\end{array}$ \\
\hline $\begin{array}{l}\text { Medium } \\
\text { Chain } \\
\text { Triglyceride }\end{array}$ & $\begin{array}{l}\text { Can be any } \\
\text { ratio } \\
\text { Based on } \\
\text { 4:1 ratio: }\end{array}$ & $\begin{array}{l}\text { Provides more protein; } \\
\text { Greater protein serving size } \\
\text { allows more } \\
\text { volume in which to mix the }\end{array}$ & $\begin{array}{l}\text { Involves weighing and measuring } \\
\text { food; } \\
\text { time-consuming to prepare the meals; } \\
\text { Gastrointestinal side effects }\end{array}$ \\
\hline
\end{tabular}




\begin{tabular}{|c|c|c|c|}
\hline & $\begin{array}{lr}10 \% & \text { LCT } \\
\text { fat, } & 60 \% \\
\text { MCT } & \\
\text { fat, } & 20 \% \\
\text { carbohydrat } \\
\text { e, } \\
10 \% \text { protein } \\
\end{array}$ & $\begin{array}{l}\text { fats and } \\
\text { increased variety of food; }\end{array}$ & \\
\hline $\begin{array}{l}\text { Modified } \\
\text { Atkins }\end{array}$ & $\begin{array}{l}\text { Approx } \\
1.1: 1 \text { ratio } \\
65 \% \text { fat, } \\
10 \% \\
\text { carbohydrat } \\
\text { e, } 25 \% \\
\text { protein }\end{array}$ & $\begin{array}{l}\text { Greater flexibility to adjust } \\
\text { meal to } \\
\text { variations in appetite; } \\
\text { Provides more protein; } \\
\text { Greater protein serving size } \\
\text { allows more } \\
\text { volume in which to mix the } \\
\text { fats; } \\
\text { Less weighing, measuring, } \\
\text { faster meal prep; }\end{array}$ & $\begin{array}{l}\text { No firm guidelines regarding fat } \\
\text { amounts; } \\
\text { Requires experimentation to determine } \\
\text { adequate fats to ensure } \\
\text { desired ketosis; } \\
\text { Often more variability in ketone } \\
\text { production; } \\
\text { Requires more record keeping to allow } \\
\text { adjustments in diet }\end{array}$ \\
\hline $\begin{array}{l}\text { Low } \\
\text { glycemic } \\
\text { index diet }\end{array}$ & $\begin{array}{l}\text { Approx } \\
0.6: 1 \text { ratio } \\
60 \% \text { fat, } \\
10 \% \\
\text { carbohydrat } \\
\text { e, } 30 \% \\
\text { protein }\end{array}$ & $\begin{array}{l}\text { Greater flexibility to adjust } \\
\text { meal to } \\
\text { variations in appetite; } \\
\text { Provides more protein; } \\
\text { Greater protein serving size } \\
\text { allows more } \\
\text { volume in which to mix the } \\
\text { fats; } \\
\text { Less weighing, measuring, } \\
\text { faster meal prep; }\end{array}$ & $\begin{array}{l}\text { Requires knowledge of the foods that } \\
\text { have low glycemic index; } \\
\text { Requires more record keeping to allow } \\
\text { adjustments in diet }\end{array}$ \\
\hline
\end{tabular}

SOURCE: Radhika et al., 2013'

\section{POLYCYSTIC OVARY SYNDROME}

Female infertility has been commonly associated with endocrine disorder caused by polycystic ovary syndrome (PCOS). ${ }^{10}$ PCOS has a prevalence of about $6-10 \%$ and is set to occur in women with obesity, insulin resistance, hyperandrogenism and ovulatory dysfunction. Insulin resistances, which present a major concern, show $85 \%$ of the PCOS patient have hyperglycemia that leads to hyperinsulinemia with majority as obese patients. The elevated glucose and insulin level could also give increased luteinizing hormone (LH), which signifies anovulation activating follicular growth arrest. Hyperglycemia and hyperinsulinemia both causes luteinizing hormone action increase and further elevate the androgenic hormone level. ${ }^{10}$

Therapeutic action of antidiabetic drugs to reduces insulin sensitivity results in reduced androgen hormonal level, which has been associated with increased ovulation rate. The patients therefore become more resistant to ovulatory induction. In hypothalamic amenorrhea and anorexia nervosa patients commonly known for low gonad secretion and damaged ovulatory function, leptin, an important adipocytokines is essential in regulating ovulatory functions. ${ }^{11}$

Biomarkers of fat metabolism could therefore be efficient on checking reproductive function because replacement of leptin could restore gonadotropin secretion, development of follicular 
growth and sometimes causes ovulation in hypothalamic amenorrhea patients.

Insulin resistance improves or completely disappear during restricted dietary carbohydrate intake, which minimizes fat synthesis. Recent studies have proven that low carbohydrate ketogenic diet improves insulin resistance and results in weight loss. ${ }^{10}$

PCOS patients have exhibited other different symptoms of metabolic symptoms other than insulin resistance and obesity; others are high inflammatory level, type 2 diabetes, glucose intolerance and dyslipidemia. Recommended treatments such as pharmacological treatment (thiazolidinediones or metformin) and lifestyle change such as diet and exercise reduces insulin resistance/hyperinsulinemia. Improvement observed in treating hyperinsulinaemia and weight lost may reduce hyperandrogenism, normalize ovulation and reduce other PCOS symptoms. ${ }^{3}$

\section{DYSLIPIDEMIA}

High content of fat is obtained in ketogenic diet; therefore evaluating the lipid profile is important in understanding dyslipidemia a known risk factor of cardiovascular diseases. ${ }^{12}$ A 14 days study on ketogenic diet reveals no alteration in the fatty acid and triglyceride levels in mice. The fed composition and period of feeding are very essential. ${ }^{13}$ Bielohuby et al., (2013) in a study carried out for 4 weeks, linked rat chow diet and two other ketogenic diet. ${ }^{14}$ The composition of the first group contains high fat of $78.7 \%, 2.2 \%$ carbohydrates and $19.1 \%$ protein while very high fat of $92.8 \%, 1.7 \%$ carbohydrates and $5.5 \%$ protein made up the second group. A decrease in the high-density lipoprotein (HDL) cholesterol levels and increased triglycerides levels in the group fed with very high ketogenic diet was observed. There is no change in all the three groups in total cholesterol levels.

Ketogenic diet intake in humans is linked to increase in HDL level and decrease in total cholesterol, triglycerides and LDL levels. ${ }^{15} \mathrm{~A}$ report by Foster and co-workers showed no significant change after a year of ketogenic diet treatment in total and LDL cholesterol level when compared to the control. This finding revealed that weight loss in relation to consumption of ketogenic diet does not correlate with reduced LDL level as seen in moderate weight loss. ${ }^{16}$

\section{OBESITY}

The link between ketogenic diet intake and obesity has been established. In a study using both obese and non-obese rats, it was observed that ketogenic diet are effective in weight loss. Garbow et al., (2011) reported a significant decrease in weight gained in chow-fed mice when compared to a high fat high carbohydrate diet fed mice. A significantly low lean mass was observed in ketogenic diet fed mice compared to chow fed mice. ${ }^{17}$

Another study also revealed that after 4 weeks of diet, visceral fat mass accumulation was significantly higher in ketogenic diet fed rats when compared to chow fed controls. The ketogenic diets used here was the modified Atkins diet and low carbohydrate ketogenic diet. ${ }^{12}$

In the research conducted by Jornayvaz et al. (2010) for 5 weeks, comparison was made between ketogenic diet fed mice and regular chow fed mice. The ketogenic diet fed group had less weight gained and high fat mass percentage than the chow fed mice. ${ }^{18}$

Long-term studies are also carried out to evaluate weight loss. A study reported that after 22 weeks of ketogenic diet intake, there was no weight loss in the end despite initial weight loss. After 80 weeks of feeding ketogenic diet to mice, there was an initial weight lost but after 18 weeks, the weight was restored and increased gradually, but weight gain was less than that of the chow fed mice. ${ }^{19}$

A study carried out for a year compared the effect of different diets on weight loss. Several diets 
including a ketogenic diet, low carbohydrate, a non-ketogenic diet and Mediterranean diet was used. Weight loss and decreased fat percentages was observed in the ketogenic diet when compared to the other diets. ${ }^{10}$ Other researchers also observed changes in digestive metabolism of ketogenic diets; appetite and ghrelin level were reduced during ketosis in the patients. ${ }^{20}$ One hundred and thirty-two obese patients with mean BMI of $43 \mathrm{~kg} / \mathrm{m}^{2}$ who had metabolic syndrome showed that those eating low carbohydrate ketogenic diet had greater weight loss than those on other diets. This signifies that a high decrease in total calorie intake is responsible for the weight loss rather than macronutrient composition. ${ }^{12}$

\section{INTRACTABLE EPILEPSY}

All over the world, there are about 50-70 million people having epilepsy with about 20-30\% resistant to drug treatment. Different factors such as treatment failure, side effects of drugs and negative consequences of seizures had prompted the use of ketogenic diet for the past 20 years. ${ }^{21,22}$ There was significant reduction in seizures in those who consumed ketogenic diet after a 3-month efficacy studies. ${ }^{21}$

\section{NEUROLOGICAL DISEASES}

Emerging data has shown some therapeutic functions of ketogenic in several neurological diseases such as epilepsy, Parkinson's disease, autism, neurotrauma, Alzheimer's disease and multiple sclerosis. The similarities between all these diseases and the efficacy of ketogenic diet could be attributed to the neuroprotective effect of the diet. The mechanism is still unknown. Ketogenic diets were initially recognized to raise ATP level and decrease reactive oxygen species production in the neurological tissues. It helps in synaptic function regulation and regulation of membrane excitability by increasing PUFA synthesis. ${ }^{23}$ Recently, Włodarek reviewed the role of ketogenic diets on neurodegenerative diseases, with focus on the Alzheimer's disease and Parkinson's disease. The available results of research projects dealing with the use of the KD and ketone bodies in neurodegenerative diseases are fairly promising. He stated that 'the available results of research projects dealing with the use of the KD and ketone bodies in neurodegenerative diseases are fairly promising. ${ }^{24}$

\section{CANCER}

Cancer is one of the leading causes of death all over the world. Many tumor-signaling pathways congregate to adjust to the metabolism that supports growth and survival of cell. Glucose is the major substrate for cellular metabolism and it concurrently reduced aerobic production of energy through oxidative phosphorylation. Warburg effect is termed as the shift by cancerous cells from oxidative phosphorylation to glycolysis. ${ }^{25}$ Cancerous cells convert metabolic glucose to pyruvate and then to lactate instead of undergoing oxidative phosphorylation from pyruvate. Glycolytic breakdown is faster than oxidative phosphorylation. ${ }^{26,27}$ Cancer cells are therefore dependent on glucose for its growth, therefore the logic behind ketogenic diet is to target cancer dependency on glucose and starve the tumor cells..$^{28,29,30}$ Glioblastoma xenografts and malignant astrocytoma growth are inhibited in mice by ketogenic diet. Ketogenic diet effect on anti-tumor radioactive therapy is enhanced in glioma patients. ${ }^{31}$

\section{LIMITATIONS, CAUTIONS AND SIDE EFFECTS OF KETOGENIC DIETS}

Psychosocial limitations include compliance difficulty, family and social support greatly needed 
and extremely prone to hearsay and superstitions. The biomedical limitations include its unsuitability for some persons because of associated side effects, it is not a balanced diet and its very long-term effects are not yet known. ${ }^{32}$

Persons with diabetes and on oral hypoglycemic or insulin medications experience very serious hypoglycemia except the treatments are changed and made suitable before the start of the diet. Ketogenic diet is not suitable for people with pancreatitis, liver failure, disorders of fat metabolism, primary carnitine deficiency, carnitine palmitoyltransferase deficiency, carnitine translocase deficiency, porphyrias, or pyruvate kinase deficiency. Alcohol breath test result is not reliable from someone on a ketogenic diet as the probability of a false positive is very high. ${ }^{33} \mathrm{~A}$ more serious challenge of the long-term use of ketogenic diet is compliance with the dietary recommendations. The high fat content in the diet could result in poor tolerance. The acute side effects include nausea and vomiting, hypoglycemia and lethargy due to excessive ketosis. The chronic side effects are gastrointestinal disorders (such as constipation, weight loss, mineral and vitamin deficiency (eg. selenium, Vitamin D, calcium) and pancreatitis) renal disorder (stones), cardiac disorder (cardiomyopathy), growth and development (short stature, osteopenia), others include low albumin, low carnitine and abnormal lipid profile (elevated cholesterol). 9,24,34 Diseases that could deteriorate when the sufferers are on ketogenic diet are porphyria, pyruvate carboxylase deficiency, unrecognized carnitine deficiency, defects in fatty acid oxidation and mitochondrial disorders. ${ }^{35}$

\section{CONCLUSION}

Ketogenic diet is gradually gaining acceptance as a therapeutic modality for many other diseases. Many metabolic disorders are being remedied with ketogenic diet. ${ }^{36}$ However, close monitoring of renal functions while on a ketogenic diet is highly imperative, and the transition from a ketogenic diet to a standard diet should be gradual and well controlled. The limitations and side effects of ketogenic diets are highlighted in this review and further research is required to develop strategies to alleviate them.

\section{REFENCES}

1. Vidalia S, Aminzadeha S, Lambert B, Rutherford T, Sperl W, Kofler B, Feichtingera R. Mitochondria: The ketogenic diet-A metabolism-based therapy. Int. J. Biochem. Cell Biol 2015;63, 55-59.

2. Kulaka, D. \& Polotsky, A. (2013). Should the ketogenic diet be considered for enhancing fertility? Maturitas, $74: 10-13$.

3. Branco AF, Ferreira A, Simoes R, Novais S, Zehowski C, Cope E, Silva A, Pereira D, Vilma S, Oliveira T. Ketogenic diets: from cancer to mitochondrial diseases and beyond. Eur J Clin Invest 2016;46 (3): 285-298.

4. Wilder R. The effects of ketonemia on the course of epilepsy. Mayo Clin Proc 1921; 2:307-8.

5. Ferreira L, Lisenko K, Barros B, Zangeronimo M, Pereira L, Sousa R. Influence of medium-chain triglycerides on consumption and weight gain in rats: a systematic review. J Anim Physiol Anim Nutr (Berl) 2014;98:1-8.

6. Giordano C, Marchio M, Timofeeva E, Biagini G. Neuroactive peptides as putative mediators of antiepileptic ketogenic diets. Front Neurol 2014; 63.

7. Wibisono C, Rowe N, Beavis E, Kepreotes H, Mackie F, Lawson J et al. Ten-year singlecenter experience of the ketogenic diet: factors influencing efficacy, tolerability, and 
compliance. J Pediatr 2015;166:1030 e1-1030 e6.

8. Auvin S. Should we routinely use modified Atkins diet instead of regular ketogenic diet to treat children with epilepsy? Seizure 2012;21:237-40.

9. Radhika D., Susan E, Elaine W. Ketogenic Diet. Can J Neurol Sci. 2013; 40: 158-167

10. Paoli A, Bianco A, Grimaldi K, Lodi A, Bosco G. Long term successful weight loss with a combination biphasic ketogenic Mediterranean diet and Mediterranean diet maintenance protocol. Nutrients 2013;5, 5205-5217.

11. Alwahab A, Pantalone KM, Burguera B. A Ketogenic Diet May Restore Fertility In Women with Polycystic Ovary Syndrome: A Case Series. AACE Clinical Case Reports 2018;4; e427.

12. Kosinski C, Jornayvaz J. Effects of Ketogenic Diets on Cardiovascular Risk Factors: Evidence from Animal and Human Studies. Nutrients 2017;9, 517; doi:10.3390/nu9050517.

13. Murata Y, Nishio K, Mochiyama T, Konishi M, Shimada M, Ohta H, Itoh N. Fgf21 Impairs Adipocyte Insulin Sensitivity in Mice Fed a Low-Carbohydrate, High-Fat Ketogenic Diet. PLoS ONE 2013;8, e69330.

14. Bielohuby M, Sisley S, Sandoval D, Herbach N, Zengin A, Fischereder M, Menhofer D, Stoehr B, Stemmer K., Wanke R, et al. Impaired glucose tolerance in rats fed lowcarbohydrate, high-fat diets. Am. J. Physiol. Endocrinol. Metab 2013;305, E1059-E1070.

15. Lima PA, de Brito Sampaio LP, Damasceno N. Ketogenic diet in epileptic children: Impact on lipoproteins and oxidative stress. Nutr. Neurosci 2015;18, 337-344.

16. Foster GD, Wyatt HR, Hill JO, McGuckin BG, Brill C, Mohammed BS, Szapary PO, Rader DJ, Edman JS, Klein SA. Randomized Trial of a Low-Carbohydrate Diet for Obesity. N. Engl. J. Med 2003;348, 2082-2090.

17. Garbow JR, Doherty JM, Schugar RC, Travers S, Weber ML, Wentz AE, Ezenwajiaku N, Cotter DG, Brunt EM, Crawford PA. Hepatic steatosis, inflammation, and ER stress in mice maintained long term on a very low-carbohydrate ketogenic diet. Am. J. Physiol. Gastrointest. Liver Physiol 2011;300, G956-G967.

18. Jornayvaz FR, Jurczak MJ. Lee HY, Birkenfeld AL, Frederick DW, Zhang D, Zhang XM, Samuel VT, Shulman GI. A high-fat, ketogenic diet causes hepatic insulin resistance in mice, despite increasing energy expenditure and preventing weight gain. Am. J. Physiol. Endocrinol. Metab 2010;299, E808-E815.

19. Douris N, Melman T, Pecherer J, Pissios P, Flier J, Cantley L, Locasale J, Maratos-Flier E. Adaptive changes in amino acid metabolism permit normal longevity in mice consuming a low-carbohydrate ketogenic diet. Biochim. Biophys. Acta 2015;1852, 20562065.

20. Saisho Y, Butler A, Manesso E, Elashoff D, Rizza R, Butler P.. Cell mass and turnover in humans. Effects of obesity and aging. Diabetes Care 2013;36, 111-117.

21. Neal EG, Cross JH. Efficacy of dietary treatments for epilepsy. J Hum Nutr Diet 2010;23:113-9.

22. Neal, E. Dietary treatment of epilepsy: practical implementation of ketogenic therapy.1st ed. Oxford, UK: Wiley-Blackwell 2012.

23. Bough KJ, Rho JM. Anticonvulsant mechanisms of the ketogenic diet. Epilepsia 2007;48: $43-58$.

24. Włodarek D. Role of Ketogenic Diets in Neurodegenerative Diseases (Alzheimer's Disease and Parkinson's Disease). Nutrients 2019, 11, 169; doi:10.3390/nu11010169 
25. Warburg O. On the origin of cancer cells. Science 1956;123:309-14.

26. Chen Z, Lu W, Garcia-Prieto C, Huang P. The Warburg effect and its cancer therapeutic implications. J Bioenerg Biomembr 2007;39:267-74.

27. Feichtinger RG, Zimmermann F, Mayr JA, Neureiter D, Hauser-Kronberger C, Schilling $\mathrm{FH}$, et al. Low aerobic mitochondrial energy metabolism in poorly - or undifferentiated neuroblastoma. BMC Cancer 2010;10:149.

28. Scheck AC, Abdelwahab MG, Fenton KE, Stafford P. The ketogenic diet for the treatment of glioma: insights from genetic profiling. Epilepsy Res 2012;100:327-37.

29. Lv M, Zhu X, Wang H, Wang F, Guan W. Roles of caloric restriction, ketogenic diet and intermittent fasting during initiation, progression and metastasis of cancer in animal models: a systematic review and meta-analysis. PLoS ONE 2014;9:e115147.

30. Zhou W, Mukherjee P, Kiebish M, Markis W, Mantis J, Seyfried T. The calorically restricted ketogenic diet, an effective alternative therapy for malignant brain cancer. Nutr Metab (Lond) 2007; 4:5.

31. Abdelwahab MG, Fenton KE, Preul MC, Rho JM, Lynch A, Stafford P., et al. The ketogenic diet is an effective adjuvant to radiation therapy for the treatment of malignant glioma. PLoS ONE 2012;7:e36197.

32. Sanjay K, Rajiv S, Rahul R, Munish D, Deepak K, Bharti K. The Ketogenic Diet. US Endocrinology. 2018;14(2):62-4.

33. Wajeed M, Kalyan RU. Ketogenic Diet. NCBI Bookshelf. A service of the National Library of Medicine, National Institutes of Health. StatPearls [Internet]. Treasure Island (FL): StatPearls Publishing; 2019 Jan-. https://www.ncbi.nlm.nih.gov/books/NBK499830.

34. Chorągiewicz T, Ziarnowska I, Gasior M, Ziarnowski T. Anticonvulsant and neuroprotective effects of the ketogenic diet. Przegląd Lekarski 2010, 67, 205-212. (In Polish).

35. Wheless JW. The Ketogenic Diet: An Effective Medical Therapy With Side Effects. Journal of Child Neurology, 2001, 16:9.

36. Kayode OT, Rotimi DE, Olaolu TD, Adeyemi OS. Ketogenic diet improves and restores redox status and biochemical indices in monosodium glutamate-induced rat testicular toxicity. Biomedicine \& Pharmacotherapy, 2020127110227. 